\title{
Oppositional Behavior
}

National Cancer Institute

\section{Source}

National Cancer Institute. Oppositional Behavior. NCI Thesaurus. Code C117261.

Negative, defiant, or hostile behavior directed towards authority. 